\title{
Dopaminergic D1 receptor signalling is necessary, but not sufficient for cued fear memory destabilisation
}

\author{
Charlotte R. Flavell ${ }^{1}$ • Jonathan L. C. Lee ${ }^{1}$ (i) \\ Received: 13 May 2019 / Accepted: 16 July 2019 / Published online: 7 August 2019 \\ (C) The Author(s) 2019
}

\begin{abstract}
Rationale Pharmacological targeting of memory reconsolidation is a promising therapeutic strategy for the treatment of fear memory-related disorders. However, the success of reconsolidation-based approaches depends upon the effective destabilisation of the fear memory by memory reactivation.

Objectives Here, we aimed to determine the functional involvement of dopamine D1 receptors in cued fear memory destabilisation, using systemic drug administration.

Results We observed that direct D1 receptor agonism was not sufficient to stimulate tone fear memory destabilisation to facilitate reconsolidation disruption by the glucocorticoid receptor antagonist mifepristone. Instead, administration of the nootropic nefiracetam did facilitate mifepristone-induced amnesia, in a manner that was dependent upon dopamine D1 receptor activation. Finally, while the combined treatment with nefiracetam and mifepristone did not confer fear-reducing effects under conditions of extinction learning, there was some evidence that mifepristone reduces fear expression irrespective of memory reactivation parameters.
\end{abstract}

Conclusions The use of combination pharmacological treatment to stimulate memory destabilisation and impair reconsolidation has potential therapeutic benefits, without risking a maladaptive increase of fear.

Keywords Reconsolidation $\cdot$ Destabilisation $\cdot$ Dopamine $\cdot$ Nefiracetam $\cdot$ Fear $\cdot$ Extinction $\cdot$ Mifepristone $\cdot$ Glucocorticoid

\section{Introduction}

The disruption of memory reconsolidation, the restabilisation of a memory destabilised following retrieval, represents a promising therapeutic approach for anxiety and traumarelated disorders. Pharmacological impairment of memory reconsolidation reduces fearful behaviour in rodents (Nader et al. 2000), fear responses in experimental human studies (Agren 2014) and clinical symptoms in patients suffering with PTSD and phobias (Brunet et al. 2011; Soeter and Kindt 2015).

While the efficacy of reconsolidation impairment appears relatively robust, targeting reconsolidation depends upon the success of destabilising the memory behaviourally via a memory reactivation session, which usually takes the form of cue re-exposure (Almeida-Correa and Amaral 2014). It is

Jonathan L. C. Lee

j.l.c.lee@bham.ac.uk

1 School of Psychology, University of Birmingham, Hills Building, Edgbaston, Birmingham B15 2TT, UK increasingly evident that successful reconsolidation impairment is far from guaranteed (Kindt and van Emmerik 2016), especially as there are unpredictable boundary conditions that govern memory destabilisation (Wideman et al. 2018). For example, we recently demonstrated that there appears to be no reliable basis upon which to predict the behavioural parameters that will trigger memory destabilisation/reconsolidation (Cassini et al. 2017). In fact, lack of replicability of reconsolidation impairments may well be due to poorly understood boundary conditions on memory destabilisation (Bos et al. 2014).

This lack of reliability of memory destabilisation raises the potential that reconsolidation-disrupting pharmacological treatment might be applied to individuals with no chance of beneficial effect (because the memory has not been destabilised and so there is no reconsolidation process to impair). This has motivated the exploration of pharmacological enhancement of memory destabilisation (Bustos et al. 2010; Gazarini et al. 2015; Lee and Flavell 2014). Here, we further explored the potential to enhance the destabilisation of cued fear memories. In spite of recent promising results (Bustos et al. 2010; Lee and Flavell 2014; Ortiz et al. 2015), we elected 
not to focus on D-cycloserine or ACEA as potentiators of destabilisation, partly due to the fact that D-cycloserine can enhance reconsolidation to strengthen fear (Lee et al. 2006) and there remains a degree of uncertainty concerning the effects of $\mathrm{CB} 1$ receptor modulation on fear memory reconsolidation (Lee et al. 2019; Lin et al. 2006; Ratano et al. 2014). Moreover, given the potential use of NMDA receptor and cannabinoid $\mathrm{CB} 1$ receptor antagonists for the impairment of reconsolidation (Fattore et al. 2018; Stern et al. 2012), separable pharmacological targets for destabilisation enhancement and reconsolidation impairment would be desirable. Therefore, we focussed on additional mechanisms that have been implicated in memory destabilisation, starting with the demonstration that dopaminergic signalling in the amygdala is necessary for appetitive Pavlovian memory destabilisation (Merlo et al. 2015). As a result, we tested whether dopamine D1 receptor agonism would enhance cued fear memory destabilisation. Moreover, we focussed on the use of the glucocorticoid antagonist mifepristone for the impairment of reconsolidation (Pitman et al. 2011), given our initial failure to replicate published findings with propranolol (Debiec and LeDoux 2004).

\section{Materials and methods}

\section{Subjects}

One hundred and eighty-eight male Lister Hooded rats (Charles River, UK; 200-225 g at the start of the experiment) were housed in quads under a 12-h light/dark cycle (lights on at 0700 ) at $21{ }^{\circ} \mathrm{C}$ with food and water provided ad libitum apart from during the behavioural sessions. The cages were individually ventilated for the animals contributing to the data in Figs. 1, 2, and 3, and were standard cages for the animals contributing to the data in Fig. 4 (due to a facility equipment change during the course of the project). The cages contained aspen chip bedding, and environmental enrichment was available in the form of a Plexiglass tunnel. Experiments took place in a behavioural laboratory between 0830 and 1300. At the end of the experiment, the animals were humanely killed via a rising concentration of $\mathrm{CO}_{2}$; death was confirmed by cervical dislocation. Principles of laboratory animal care were followed, as approved by the University of Birmingham Animal Welfare and Ethical Review Body and in accordance with the United Kingdom Animals (Scientific Procedures) Act 1986, Amendment Regulations 2012 (PPLs P8B15DC34 \& P3B19D9B2).

\section{Drugs}

All drugs were administered systemically at previously established doses and timepoints. Mifepristone (Generon,
UK) was injected at $30 \mathrm{mg} / \mathrm{kg}(60 \mathrm{mg} / \mathrm{ml}$ in propylene glycol, s.c.) immediately after memory reactivation (Pitman et al. 2011). DL-propranolol (Sigma, UK) was injected at $10 \mathrm{mg} / \mathrm{kg}(10 \mathrm{mg} / \mathrm{ml}$ in saline, i.p.) immediately after reactivation (Debiec and LeDoux 2004; Pitman et al. 2011). (+/-)SKF38393 (Sigma, UK) was injected at $5 \mathrm{mg} / \mathrm{kg}(5 \mathrm{mg} / \mathrm{ml}$ in $5 \%$ DMSO in saline, i.p.) $5 \mathrm{~min}$ before reactivation (de Lima et al. 2011). Nefiracetam (Sigma, UK) was injected at $3 \mathrm{mg} / \mathrm{kg}$ (6 $\mathrm{mg} / \mathrm{ml}$ in saline, i.p.) $1 \mathrm{~h}$ before reactivation (Yoshii et al. 1997). SCH23390 (Tocris, UK) was injected at $0.1 \mathrm{mg} / \mathrm{kg}$ $(0.1 \mathrm{mg} / \mathrm{ml}$ in saline, i.p.) $30 \mathrm{~min}$ before reactivation (Heath et al. 2015). Modafinil (Sigma, UK) was injected at $5 \mathrm{mg} / \mathrm{kg}$ (10 $\mathrm{mg} / \mathrm{ml}$ in $50 \%$ DMSO in saline, i.p.) $60 \mathrm{~min}$ prior to reactivation (Shanmugasundaram et al. 2015). All i.p. injections were administered to the same (right) side of the abdomen. Allocation to drug treatment was fully randomised within each experimental cohort of 8 rats.

\section{Behavioural procedures}

Rats were conditioned and tested individually in two identical conditioning chambers (MedAssociates, VT) described previously (Lee et al. 2019). They were initially habituated to the conditioning chamber for $1 \mathrm{~h}$. On the next day, they received a further 20-min habituation, followed by a single presentation of a single $30-\mathrm{s}, 1.5-\mathrm{kHz}$ tone, co-terminating with a $1-\mathrm{s}$ (or $0.5-\mathrm{s}), 0.4-\mathrm{mA}$ footshock. There was a 2-min recovery period following the footshock delivery. Twenty-four hours after training, the tone fear memory was reactivated by representing the tone once for $60 \mathrm{~s}$ (the longer duration aiming to maximise prediction error) (Fernandez et al. 2016), after a 60 -s pre-CS period. Twenty-four hours after reactivation, conditioned freezing to the tone was assessed in a session identical to reactivation.

For the extinction experiment, all procedures were the same (with the 1-s footshock delivery) apart from the session $24 \mathrm{~h}$ after training. Rats were exposed to ten 60 -s tone presentations, after a 60 -s pre-CS period and with 60 -s intervals between each tone presentation (Lee et al. 2006).

\section{Statistical analyses}

Data are presented as \% time freezing (+ SEM) during the preCS period and tone presentation of the test. Nine subjects were excluded from the extinction experiment analyses due to equipment malfunction; 6 subjects were excluded as the primary endpoint was $>2$ s.d. from the group mean. The data were analysed in JASP (JASP Team 2016) by repeatedmeasures ANOVA with Group and Phase (pre-CS vs. CS periods) as factors, followed by analyses of simple main effects of group at each phase. For the extinction experiment, the analysis used nefiracetam and mifepristone as separate factors in a 3-way repeated-measures ANOVA. Given the nature of 
Fig. 1 Systemic administration of mifepristone, but not propranolol, impaired the reconsolidation of weak, but not strong, tone fear memory. After conditioning with a 0.5 -s footshock, post-

reactivation mifepristone (a), but not propranolol (b), impaired conditioned freezing to the tone, but not during the pre-CS period. After conditioning with a 1-s footshock, neither mifepristone (c) nor propranolol (d) impaired freezing during the pre-CS or tone periods. Data presented as mean $+\operatorname{SEM}(n=7$ per group $)$ a

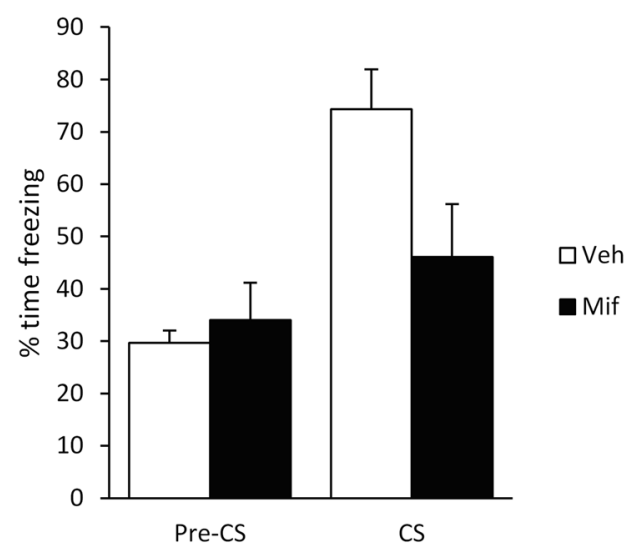

C

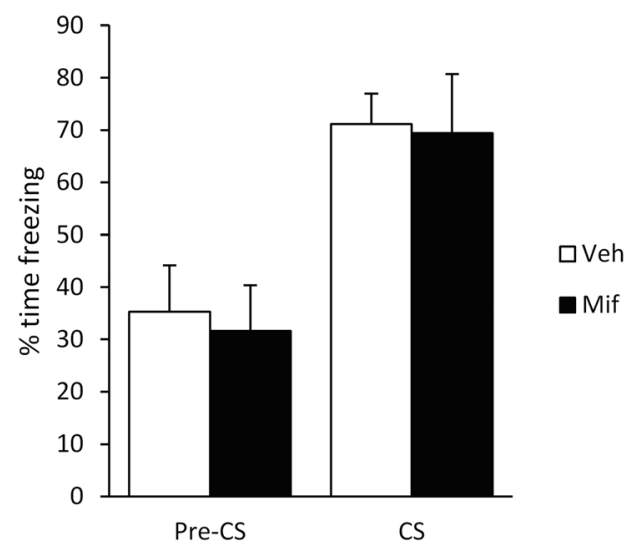

b

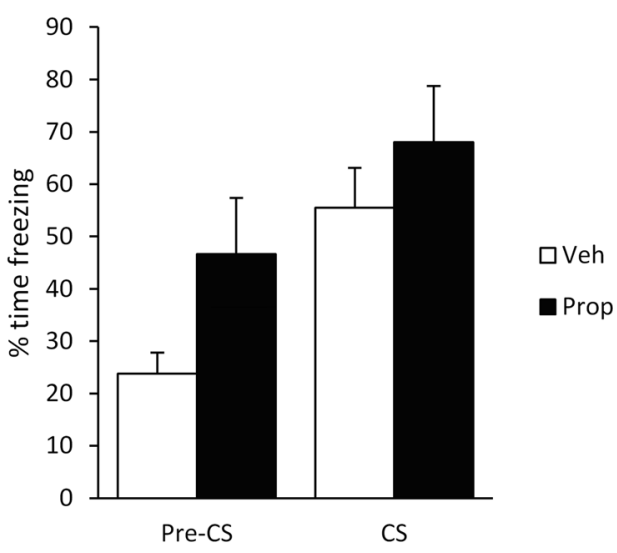

d

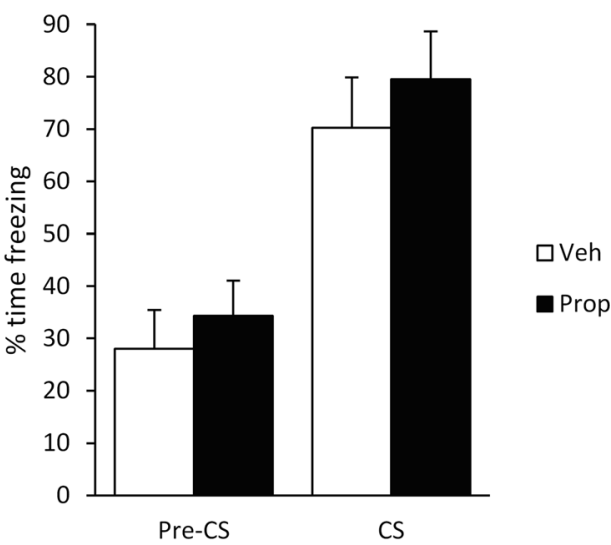

the effects observed at test, additional analyses of the extinction session, as well as an exploratory ANCOVA (with performance at extinction included as the covariate), were conducted. The primary analyses were frequentist, with alpha $=$ 0.05 and either Cohen's $d$ or $\eta_{\mathrm{p}}^{2}$ reported as an index of effect size, and the data were initially checked for normality. Significant group effects were explored with Tukey's posthoc pairwise comparisons. We also report $B F_{\text {Inclusion }}$ and $B F_{10}$ from parallel Bayesian analyses (Cauchy prior $r=$ 0.707 ) as an estimate of posterior probability, with post-hoc tests as appropriate.

\section{Results}

First, we showed that mifepristone, but not propranolol, was effective at impairing tone fear memory reconsolidation. Under weak single-trial conditioning parameters $(0.5$-s, $0.4-$ $\mathrm{mA}$ footshock), immediate post-reactivation injection of mifepristone, but not propranolol, impaired subsequent freezing to the conditioned tone at test (Fig. 1a,b). With mifepristone, there was a significant group $\times$ phase interaction $(F(1,12)=$ $\left.16.0, p=0.002, \eta_{\mathrm{p}}^{2}=0.57, B F_{\text {Inc }}=28.0\right)$, with a simple main effect of group in freezing to the CS $(t(12)=2.42, p=0.032$, $\left.d=1.29, B F_{10}=2.35\right)$, but not in the pre-CS period $(t(12)=$ $\left.0.63, p=0.54, d=0.34, B F_{10}=0.51\right)$. In contrast, with propranolol, there were no group $\times$ phase interaction $(\mathrm{F}(1,12)=$ $\left.0.66, p=0.43, \eta_{\mathrm{p}}^{2}=0.05, B F_{\text {Inc }}=1.74\right)$ and no main effect of group $\left(\mathrm{F}(1,12)=3.46, p=0.08, \eta_{\mathrm{p}}^{2}=0.22, B F_{\mathrm{Inc}}=1.46\right)$. Moreover, planned analyses of simple main effects of group revealed no differences in freezing to the CS $(t(12)=1.03, p=$ $0.33, d=0.55, B F_{10}=0.63$ ), although it was not absolutely clear that there were no group differences in the pre-CS period $\left(t(12)=2.15, p=0.053, d=1.15, B F_{10}=1.7\right)$. The disruptive effect of mifepristone was not replicated with stronger conditioning (1.0-s, 0.4-mA footshock, Fig. 1c,d). Post-reactivation injection of neither mifepristone nor propranolol had an effect on subsequent tone freezing. There were no group $\times$ phase interactions (mifepristone: $\mathrm{F}(1,12)=0.041, p=0.84, \eta_{\mathrm{p}}^{2}=$ $0.003, B F_{\text {Inc }}=0.61$; propranolol: $\mathrm{F}(1,12)=0.61, p=0.81$, $\eta_{\mathrm{p}}^{2}=0.005, B F_{\text {Inc }}=0.67$ ) or main effects of group (mifepristone: $\mathrm{F}(1,12)=0.066, p=0.80, \eta_{\mathrm{p}}^{2}=0.005, B F_{\text {Inc }}=0.61$; propranolol: $\mathrm{F}(1,12)=0.73, p=0.41, \eta_{\mathrm{p}}^{2}=0.06, B F_{\text {Inc }}=$ 0.58). Planned analyses of simple main effects confirmed no 
a

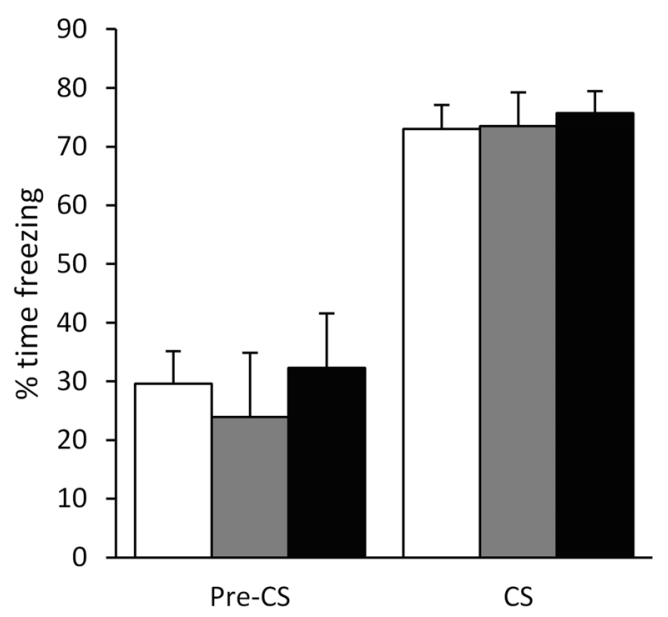

b

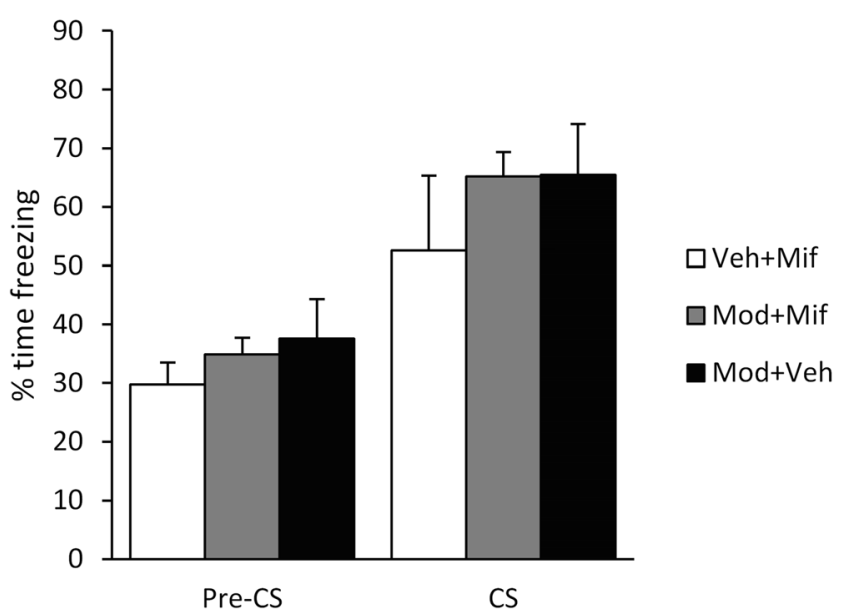

Fig. 2 Enhancement of dopaminergic signalling did not stimulate fear memory destabilisation. After conditioning with a 1-s footshock, prereactivation SKF38393 (a; $n \mathrm{~s}=13$ [Veh + Mif], $7[\mathrm{SKF}+\mathrm{Mif}]$ and 8 $[\mathrm{SKF}+\mathrm{Veh}])$ and modafinil $(\mathbf{b} ; n \mathrm{~s}=7$ [Veh + Mif], 7 [Mod + Mif $]$ and 8 [Mod + Veh] ) did not facilitate disruption of tone, or pre-CS, freezing by post-reactivation mifepristone, when compared to mifepristone and SKF38393 or modafinil alone. Data presented as mean + SEM

group differences in freezing to the CS (mifepristone: $t(12)=$ $0.15, p=0.89, d=0.08, B F_{10}=0.45$; propranolol: $t(12)=$ $0.75, p=0.47, d=0.40, B F_{10}=0.54$ ) or in the pre-CS period (mifepristone: $t(12)=0.75, p=0.89, d=0.17, B F_{10}=0.46$; propranolol: $t(12)=0.68, p=0.51, d=0.37, B F_{10}=0.52$ ). Therefore, our stronger conditioning parameters represent a boundary condition on tone fear memory reconsolidation, presumably under which our reactivation parameters were insufficient to destabilise the memory and render it vulnerable to the amnestic effect of mifepristone.

Next, we tested whether pre-treatment with the D1R agonist SKF38393 would facilitate memory destabilisation and thereby render even the stronger tone fear memory vulnerable to disruption by mifepristone. The combination of pre- a

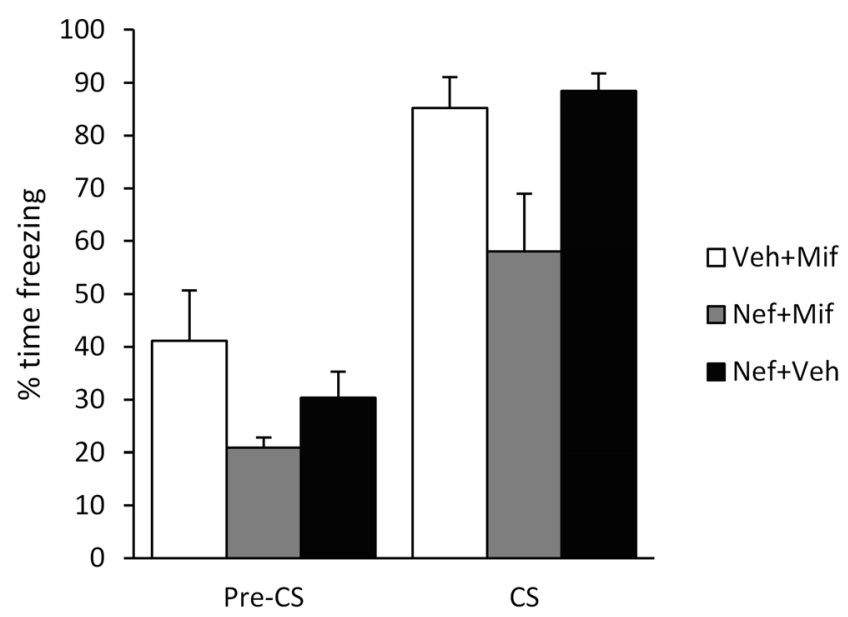

b

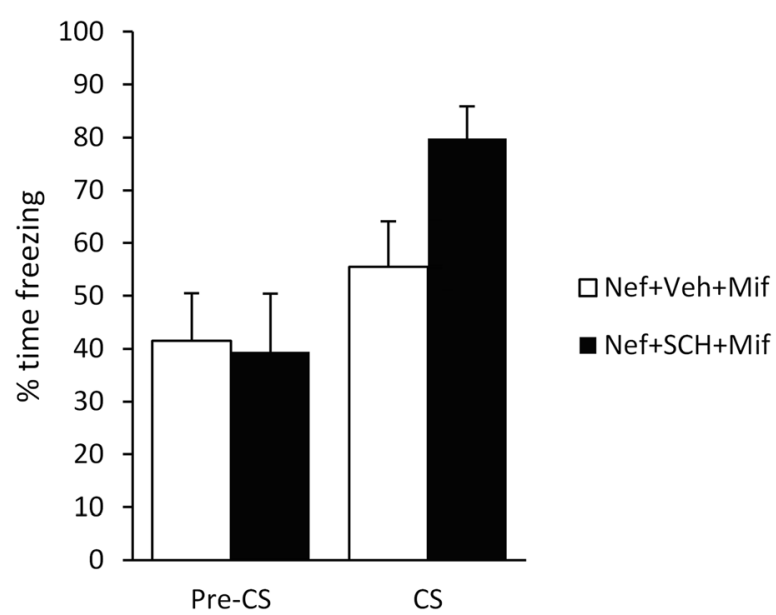

Fig. 3 Systemic administration of nefiracetam stimulated fear memory destabilisation in a dopamine D1 receptor-dependent manner. After conditioning with a 1-s footshock, pre-reactivation nefiracetam facilitated disruption of tone, but not pre-CS, freezing by post-reactivation mifepristone, when compared to mifepristone and nefiracetam alone $(\mathbf{a} ; n=7$ per group). When pre-reactivation treatment consisted of nefiracetam and SCH23390, mifepristone no longer impaired tone or pre-CS freezing (b; $n=8$ per group). Data presented as mean $+\mathrm{SEM}$

reactivation SKF38393 and post-reactivation mifepristone had no effect on test tone freezing compared to both SKF38393 + vehicle and vehicle + mifepristone (Fig. 2a; group $\times$ phase: $\mathrm{F}(2,25)=0.13, p=0.88, \eta_{\mathrm{p}}^{2}=0.01, B F_{\mathrm{Inc}}=$ 0.19 ; group: $\mathrm{F}(2,25)=0.23, p=0.80, \eta_{\mathrm{p}}^{2}=0.02, B F_{\mathrm{Inc}}=0.20$; simple main effect of group on CS freezing: $\mathrm{F}(2,25)=0.03$, $p=0.97, \eta_{\mathrm{p}}^{2}=0.003, B F_{\text {Inc }}=0.23$; simple main effect of group on pre-CS freezing: $\mathrm{F}(2,25)=0.48, p=0.62, \eta_{\mathrm{p}}^{2}=$ $0.037, B F_{\text {Inc }}=0.30$ ). Numerical comparison with the previous groups receiving vehicle or mifepristone alone indicates that neither SKF38393 nor mifepristone in isolation had a disruptive effect on subsequent tone freezing. 
Fig. 4 Effects of pre-extinction nefiracetam and post-extinction mifepristone. After conditioning with a 1-s footshock, nefiracetam was injected systemically prior to extinction and mifepristone immediately after extinction. At test, mifepristone reduced freezing to the tone, while nefiracetam increased freezing in both the pre$\mathrm{CS}$ and tone periods (a). While there was no acute effect of preextinction nefiracetam at the extinction session, there was a preexisting difference between the groups subsequently administered mifepristone compared to vehicle (b). Data presented as mean \pm $\operatorname{SEM}(n=8$ per group) a

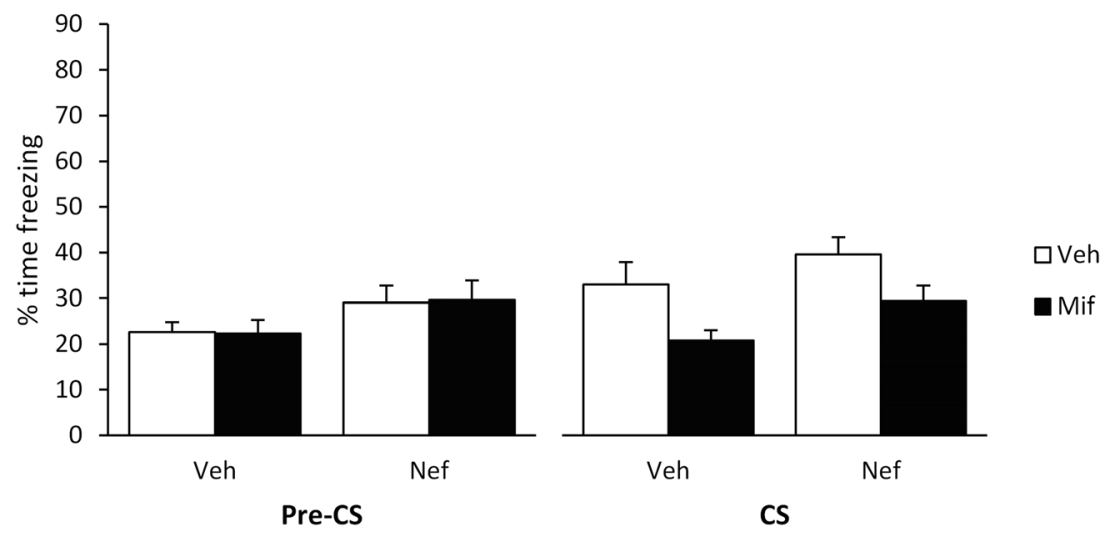

b

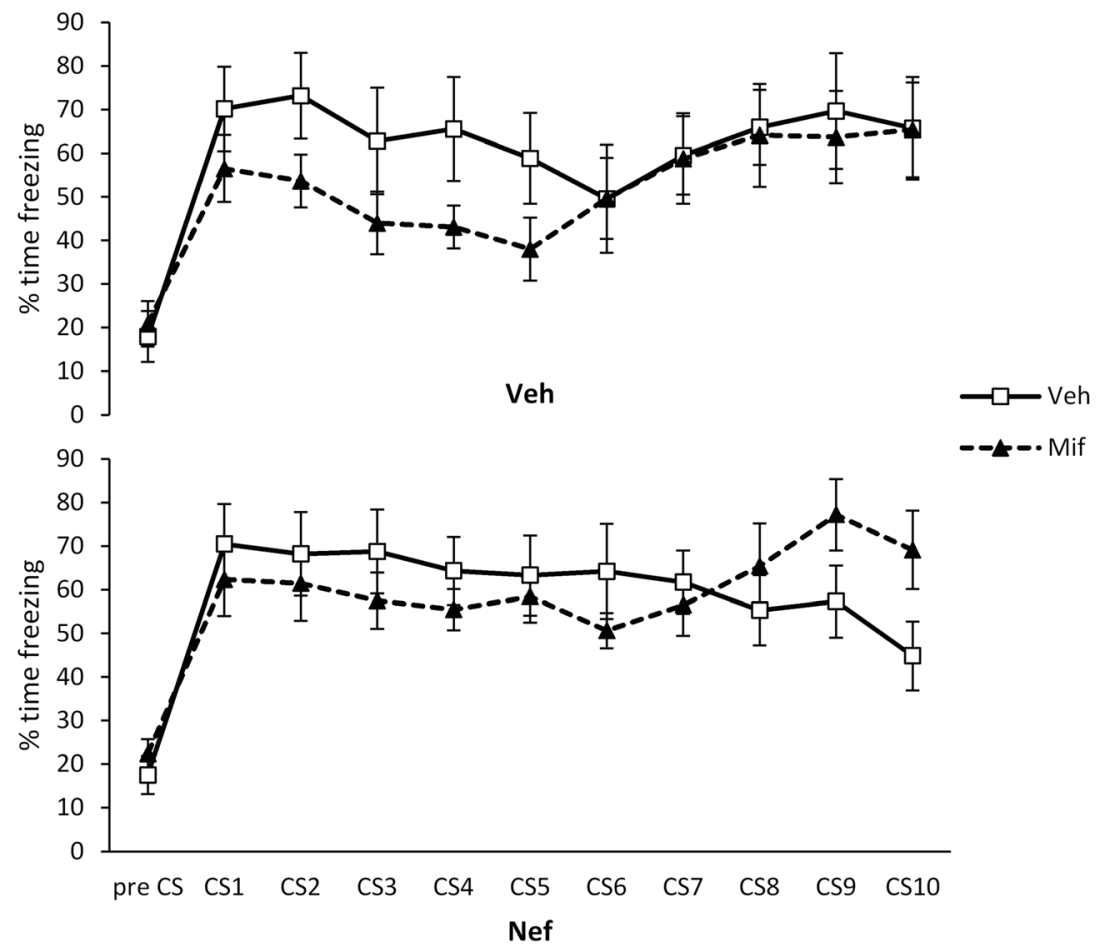

We also tested whether the less selective approach of pre-treatment with the dopamine transporter blocker modafinil would facilitate memory destabilisation. The combination of pre-reactivation modafinil and postreactivation mifepristone had no effect on test tone freezing compared to both modafinil + vehicle and vehicle + mifepristone (Fig. 2b; group $\times$ phase: $\mathrm{F}(2,19)=0.20$, $p=0.82, \eta_{\mathrm{p}}^{2}=0.02, B F_{\text {Inc }}=0.35$; group: $\mathrm{F}(2,19)=1.06$, $p=0.37, \eta_{\mathrm{p}}^{2}=0.10, B F_{\mathrm{Inc}}=0.37$; simple main effect of group on CS freezing: $\mathrm{F}(2,19)=0.73, p=0.50, \eta_{\mathrm{p}}^{2}=$ $0.071, B F_{\text {Inc }}=0.39$; simple main effect of group on preCS freezing: $\mathrm{F}(2,19)=0.75, p=0.49, \eta_{\mathrm{p}}^{2}=0.073$, $B F_{\text {Inc }}=0.40$ ). Numerical comparison with the previous groups receiving vehicle or mifepristone alone again indicated that neither modafinil nor mifepristone in isolation had a disruptive effect on subsequent tone freezing.

Given that selective agonism of D1 dopamine receptors or enhancement of dopaminergic neurotransmission did not appear to facilitate destabilisation, we adopted a broader spectrum approach, using the nootropic nefiracetam, which has effects on not only monoaminergic systems (Luthman et al. 1994) but also cholinergic signalling (Oyaizu and Narahashi 1999) and calcium channels (Yoshii and Watabe 1994), both of which have been implicated in memory destabilisation (Stiver et al. 2015; Suzuki et al. 2008). The combination of pre-reactivation nefiracetam and post-reactivation mifepristone reduced test freezing (Fig. 3a; group: $\mathrm{F}(2,18)=7.09$, $p=0.005, \eta_{\mathrm{p}}^{2}=0.44, B F_{10}=6.0 ;$ phase $\times$ group: $\mathrm{F}(2,18)=$ 
1.62, $\left.p=0.23, \eta_{\mathrm{p}}^{2}=0.15, B F_{\text {Inc }}=2.48\right)$. Analysis of simple main effects confirmed reduced freezing in the nefiracetam + mifepristone group to the tone compared to both nefiracetam + vehicle and vehicle + mifepristone $(\mathrm{F}(2,18)=5.96, p=0.010$, $\eta_{\mathrm{p}}^{2}=0.40, B F_{\text {Inc }}=5.6$; post-hoc $p<0.05, B F_{10(\mathrm{Nef}+\text { Mif vs }}$ Veh + Mif $)=2.2, B F_{10}(\mathrm{Nef}+$ Mif vs Nef + Veh $\left.)=4.1\right)$. The latter two groups froze at test at numerically higher levels to the vehicle and mifepristone groups in the previous experiment (nef+ veh $=88.5 \pm 3.3 ;$ veh + mif $=85.2 \pm 5.8 ;$ veh $=71.1 \pm 5.9$; mif $=69.4 \pm 11.3$ ), suggesting again that neither nefiracetam nor mifepristone in isolation had a disruptive effect on subsequent tone freezing. Simple main effects revealed no significant effect of group on freezing in the pre-CS period $\left(\mathrm{F}(2,18)=3.01, p=0.074, \eta_{\mathrm{p}}^{2}=0.25, B F_{10}=1.4\right.$; post-hoc $p \mathrm{~s}>0.06, B F_{10(\mathrm{Nef}+\text { Mif vs Veh }+ \text { Mif })}=1.9, B F_{10(\mathrm{Nef}+\text { Mif vs }}$ $\mathrm{Nef}+\mathrm{Veh})=1.3$ ). However, as there was no strong evidence for a selective effect on tone freezing and poor evidence that nefiracetam + mifepristone did not impact upon pre-CS freezing, we conducted an exploratory ANCOVA, with pre-CS freezing as the covariate. This analysis confirmed the disruptive effect of nefiracetam + mifepristone on tone freezing $\left(\mathrm{F}(2,17)=4.23, p=0.032, \eta_{\mathrm{p}}^{2}=0.33, B F_{\text {Inc }}=4.5\right)$.

While the mechanism of action of nefiracetam to facilitate memory destabilisation remains unclear, we focussed again on signalling at D1 dopamine receptors, testing whether such signalling is necessary for the enhancement of memory destabilisation. Co-pre-treatment with SCH23390 and nefiracetam blocked the facilitation of memory destabilisation. A nefiracetam-SCH23390-mifepristone group froze at higher levels at test relative to a nefiracetamvehicle-mifepristone comparison group (Fig. 3b). There was a significant group $\times$ phase interaction $(\mathrm{F}(1,14)=5.96, p=$ $\left.0.029, \eta_{\mathrm{p}}^{2}=0.30, B F_{\text {Inc }}=4.1\right)$, with a simple main effect of group in freezing to the $\operatorname{CS}(t(14)=2.48, p=0.026, d=1.24$, $\left.B F_{10}=2.7\right)$, but not in the pre-CS period $(t(14)=0.88, p=$ $0.88, d=-0.08, B F_{10}=0.43$ ).

Given that the neurochemical mechanisms of destabilisation, reconsolidation and extinction overlap greatly and that pharmacological approaches that impair reconsolidation can also disrupt extinction to maintain fear (Lee et al. 2006), we tested whether nefiracetam + mifepristone, or either drug individually, would affect extinction learning/consolidation. Nefiracetam and mifepristone were administered at the same timepoints relative to the extinction session as they had been in the previous reconsolidation experiments. There was an effect of mifepristone to reduce freezing to the tone, regardless of nefiracetam administration (Fig. $4 \mathrm{a}$; phase $\times$ mifepristone: $\mathrm{F}(1,28)=7.92, p=0.009, \eta_{\mathrm{p}}^{2}=0.22$, $B F_{\text {Inc }}=10.9$; phase $\times$ nefiracetam $\times$ mifepristone: $\mathrm{F}(1,14)=$ $\left.0.022, p=0.88, \eta_{\mathrm{p}}^{2}=0.001, B F_{\text {Inc }}=0.39\right)$, although it was not clear that this effect of mifepristone on freezing to the tone was seen individually in both nefiracetam (phase $\times$ mifepristone: $\mathrm{F}(1,14)=4.36, p=0.056, \eta_{\mathrm{p}}^{2}=0.24, B F_{\text {Inc }}=1.54$; mifepristone on tone freezing: $t(14)=2.13, p=0.051, d=$ 1.07, $B F_{10}=1.7$; mifepristone on pre-CS freezing: $(t(14)=$ $\left.0.10, p=0.92, d=0.05, B F_{10}=0.43\right)$ and vehicle (phase $\times$ mifepristone: $\mathrm{F}(1,14)=3.71, p=0.075, \eta_{\mathrm{p}}^{2}=0.21$, $B F_{\text {Inc }}=1.88$; mifepristone on tone freezing: $t(14)=2.43, p=$ $0.029, d=1.22, B F_{10}=2.5$; mifepristone on pre-CS freezing: $\left(t(14)=0.086, p=0.93, d=0.04, B F_{10}=0.43\right)$ conditions. Therefore, post-extinction mifepristone appears to reduce freezing to the tone CS.

We also observed an effect of nefiracetam to increase test freezing, irrespective of mifepristone administration (nefiracetam: $\mathrm{F}(1,28)=7.54, p=0.010, \eta_{\mathrm{p}}^{2}=0.21, B F_{\mathrm{Inc}}=$ 3.10; phase $\times$ nefiracetam: $\mathrm{F}(1,28)=0.031, p=0.86, \eta_{\mathrm{p}}^{2}=$ $\left.0.001, B F_{\text {Inc }}=0.69\right)$. This effect was observed across both tone $\left(\mathrm{F}(1,28)=4.80, p=0.037, \eta_{\mathrm{p}}^{2}=0.15, B F_{\text {Inc }}=1.85\right)$ and pre-CS $\left(\mathrm{F}(1,28)=4.75, p=0.038, \eta_{\mathrm{p}}^{2}=0.15, B F_{\text {Inc }}=4.03\right)$ periods. Further analysis suggested that the effect of nefiracetam on tone freezing was observed more clearly in mifepristone- $\left(t(14)=2.27, p=0.039, d=1.14, B F_{10}=2.05\right)$ than vehicle-treated rats $(t(14)=1.14, p=0.28, d=0.57$, $B F_{10}=0.65$ ). Moreover, the effect of nefiracetam on pre-CS freezing was not obvious when the two subgroups were analysed independently (mifepristone: $t(14)=1.50, p=0.16$, $d=0.75, B F_{10}=0.89$; vehicle: $t(14)=1.61, p=0.13, d=0.80$, $\left.B F_{10}=0.98\right)$. Therefore, it remains unclear what is the major factor underpinning the elevation of freezing with nefiracetam.

Because the effect of nefiracetam appeared to occur whether or not mifepristone was subsequently administered, we checked whether pre-extinction nefiracetam had an acute effect at the extinction session that might have persisted to the test (Fig. 4b). Analysis of the pre-CS period at the extinction session revealed no effect of nefiracetam or mifepristone (nefiracetam $\times$ mifepristone: $\mathrm{F}(1,26)=0.049, p=0.83, \eta_{\mathrm{p}}^{2}=$ $0.002, B F_{\text {Inc }}=0.14$; nefiracetam: $\mathrm{F}(1,26)=0.014, p=0.91$, $\eta_{\mathrm{p}}^{2}=0.001, B F_{\text {Inc }}=0.26$; mifepristone: $\mathrm{F}(1,26)=0.77, p=$ $\left.0.39, \eta_{\mathrm{p}}^{2}=0.029, B F_{\text {Inc }}=0.35\right)$. Analysis of freezing across the 10 tone presentations revealed no evidence for an acute effect of nefiracetam (tone $\times$ nefiracetam: $\mathrm{F}(2.6,66.6)=0.96$, $p=0.41, \eta_{\mathrm{p}}^{2}=0.035, B F_{\text {Inc }}=0.02$; nefiracetam: $\mathrm{F}(1,26)=$ $\left.0.23, p=0.64, \eta_{\mathrm{p}}^{2}=0.009, B F_{\text {Inc }}=0.15\right)$. However, the analysis also revealed that there potentially were pre-existing differences at the extinction session between the groups subsequently administered with mifepristone (tone $\times$ mifepristone: $\mathrm{F}(2.6,66.6)=2.30, p=0.095, \eta_{\mathrm{p}}^{2}=0.081, B F_{\text {Inc }}=0.48 ; \mathrm{mi}^{-}$ fepristone: $\mathrm{F}(1,26)=0.89, p=0.36, \eta_{\mathrm{p}}^{2}=0.033, B F_{\text {Inc }}=$ $0.30)$. Given that there appeared to be a small, albeit statistically non-significant, difference at the extinction session, we conducted an exploratory ANCOVA in order to determine whether the effect of mifepristone at test might be, at least in part, caused by pre-existing group differences. This analysis confirmed that, including freezing to the first tone at extinction as a covariate, there remained a significant effect of 
mifepristone $\left(\mathrm{F}(1,25)=7.06, p=0.014, \eta_{\mathrm{p}}^{2}=0.22, B F_{\text {Inc }}=\right.$ $5.14)$, as well as weaker evidence for an effect of nefiracetam $\left(\mathrm{F}(1,25)=4.62, p=0.041, \eta_{\mathrm{p}}^{2}=0.16, B F_{\text {Inc }}=1.85\right)$.

Because the question of importance is whether the putatively beneficial therapeutic administration of nefiracetam and mifepristone on destabilisation and reconsolidation might have alternative, and perhaps negative, effects if behavioural parameters promote extinction, we directly compared the nefiracetam + mifepristone group against the vehicle + vehicle group. There was little evidence for a reduction in tone freezing (phase $\times$ group: $\mathrm{F}(1,14)=3.73, p=0.074, \eta_{\mathrm{p}}^{2}=0.21$, $B F_{\text {Inc }}=1.06$; tone freezing: $t(14)=0.65, p=0.53, d=0.33$, $B F_{10}=0.49$; pre-CS freezing: $(t(14)=1.55, p=0.14, d=0.77$, $B F_{10}=0.92$ ). For consistency, we again conducted an exploratory ANCOVA, which confirmed no difference between the groups $\left(\mathrm{F}(1,11)=0.069, p=0.80, \eta_{\mathrm{p}}^{2}=0.006, B F_{\text {Inc }}=0.48\right)$. Therefore, the potentially beneficial effect of mifepristone and the contrasting negative effect of nefiracetam appear to interact with co-administration of the two drugs to result in no overall impact on freezing at test.

\section{Discussion}

Our results show evidence that the combination of prereactivation systemic injection of nefiracetam and postreactivation systemic mifepristone reduced fear expression to a fear conditioned tone. This disruptive effect was not observed following administration of either drug alone or when nefiracetam was replaced by either the D1 dopamine receptor agonist SKF38393 or the dopamine receptor blocker modafinil. However, co-administration of the D1 dopamine receptor antagonist SCH23390 with nefiracetam and mifepristone eliminated the disruption of fear memory expression. The disruptive effect of nefiracetam and mifepristone was not replicated when an extinction session was used instead of memory reactivation. These results indicate that a combination treatment approach of nefiracetam to enhance memory destabilisation and mifepristone to impair reconsolidation may be effective for a reconsolidation-based treatment of fear memory disorders, without the risk of potentially counterproductive effects on extinction. However, the precise mechanism of action of the experimental amnesia induced by this dual drug treatment remains unclear.

Systemic administration of mifepristone appeared to impair the reconsolidation of cued fear memoires under various conditions. We have previously used our current protocol to demonstrate that systemic administration of the NMDA receptor antagonist MK-801 impaired cued fear memory reconsolidation (Lee et al. 2006). Moreover, mifepristone has previously been shown to impair the reconsolidation of cued fear memories (Jin et al. 2007; Pitman et al. 2011), although it has yet to be successfully translated to a human clinical setting (Wood et al. 2015). While we did not include a formal non-reactivation control condition (Dudai 2004), the fact that mifepristone only disrupted freezing to the conditioned tone under certain parametric conditions rules out non-specific interpretations of the amnestic effect (see also Cassini et al. 2017).

The failure of propranolol to impair fear memory expression at test under either of the two parametric conditions used here is somewhat surprising, given the previous evidence that propranolol does impair fear memory reconsolidation (Debiec and LeDoux 2004; Kindt et al. 2009; Ortiz et al. 2015). However, there are reports of failures to replicate the disruptive effect of propranolol in fear memories (Bos et al. 2014; Muravieva and Alberini 2010; Pitman et al. 2011), as well as evidence that, at least in human studies, post-reactivation propranolol is less effective than pre-reactivation administration in impairing fear memory reconsolidation (Thomas et al. 2017). Given that mifepristone and propranolol had differential effects under identical parametric conditions, it is unlikely that the failure of propranolol here to disrupt fear memory reconsolidation represents a boundary condition on memory destabilisation. Therefore, it is perhaps more likely that the post-reactivation timing, and systemic injection nature, of propranolol administration explains the lack of disruptive effect. While it remains unclear why there was no evidence for an impairing effect of propranolol, the advantageous effect of mifepristone (see also Pitman et al. 2011) provided the basis for further exploration.

Under the stronger fear conditioning parameters, prereactivation systemic injection of nefiracetam rendered the post-reactivation administration of mifepristone effective in disrupting fear memory reconsolidation. The use of prereactivation pharmacological adjunctive treatment to facilitate reconsolidation impairments by other treatment has previously been demonstrated for stronger contextual fear memories (Lee and Flavell 2014) and cued fear memories under conditions of ethanol withdrawal (Ortiz et al. 2015) and prior stress (Bustos et al. 2010). The common interpretation is that the additional pharmacological treatment facilitates memory destabilisation, rather than having an additive amnestic effect. Indeed the use of the cannabinoid CB1 receptor agonist ACEA (Lee and Flavell 2014) and the NMDA receptor partial agonist D-cycloserine (Bustos et al. 2010; Ortiz et al. 2015) in previous studies was predicated on prior evidence that $\mathrm{CB} 1$ and GluN2B receptors are necessary for memory destabilisation (Ben Mamou et al. 2006; Suzuki et al. 2008).

The mechanism of action by which nefiracetam putatively enhances fear memory destabilisation remains somewhat unclear. The aforementioned clear bidirectional effects of $\mathrm{CB} 1$ and NMDA (GluN2B) receptor modulation on memory destabilisation (Ben Mamou et al. 2006; Lee and Flavell 2014; Ortiz et al. 2015; Suzuki et al. 2008) have not been replicated here, in that the necessity for dopamine D1 receptor 
activation for cued fear memory destabilisation (Merlo et al. 2015) was not complemented here by any evidence that D1 receptor activation with SKF38393 is sufficient to enhance destabilisation. This is in spite of further evidence in the current study that D1 receptors are necessary for destabilisation under our experimental conditions. Co-administration of SCH23390 blocked the facilitative effect of nefiracetam, rendering mifepristone ineffective at impairing reconsolidation. This further suggests that D1 receptor activation is a necessary, but not the sole functional mechanism of action of nefiracetam to enhance destabilisation. It does not appear to be the case that the insufficiency of D1 receptor activation simply reflects the additional necessity of $\mathrm{D} 2$ receptor activation (Merlo et al. 2015), as the elevation of synaptic dopamine levels by modafinil-induced blockade of the dopamine transporter was similarly ineffective. This raises the question of whether nefiracetam acts up- or down-stream of D1 receptor activation. Acute administration of nefiracetam does elevate monoamine (including dopamine) levels under certain conditions (Luthman et al. 1994). However, nefiracetam also appears to augment intracellular memory-related processes to facilitate memory consolidation (Doyle et al. 1996; Nishizaki et al. 1998), raising the possibility that nefiracetam might enhance subthreshold intracellular destabilisation processes under boundary conditions of reconsolidation. The effect of co-administration of SCH23390 would then suggest that the subthreshold intracellular destabilisation results from an insufficient activation of D1 receptors, but this again is inconsistent with the failure of SKF38393 to enhance destabilisation.

The lack of effect of both SKF38393 and modafinil suggests that there are non-dopaminergic mechanisms of action of nefiracetam. One highly likely additional mechanism of action is via L-type voltage-gated calcium channels (LVGCCs). Blockade of LVGCCs with systemic injections of nimodipine has been shown to prevent contextual fear memory destabilisation (De Oliveira Alvares et al. 2013; Suzuki et al. 2008), and nefiracetam has pharmacological effects to enhance LVGCC calcium currents (Yoshii and Watabe 1994). Therefore, we would predict that co-administration of nimodipine would replicate the effect of $\mathrm{SCH} 23390$ to prevent the enhancement of destabilisation by nefiracetam. A further possibility is that nefiracetam acts though cholinergic receptors, via an elevation of extracellular acetylcholine (Sakurai et al. 1998). While cholinergic receptors have not to our knowledge been studied in relation to fear memory destabilisation, and dysregulation of cholinergic signalling has instead been demonstrated to disrupt restabilisation (Boccia et al. 2004; Boccia et al. 2006), activation of muscarinic acetylcholine receptors is sufficient to enhance destabilisation of object recognition memories (Stiver et al. 2015). Moreover, it is possible that activation of nicotinic acetylcholine receptors also contributes to object memory destabilisation (Stiver et al. 2015), and, so, the identified action of nefiracetam to elevate acetylcholine-induced currents at nicotinic acetylcholine receptors (Oyaizu and Narahashi 1999) may contribute to the destabilisation of cued fear memories. However, perhaps the most likely mechanism of action is via NMDA receptors, given the effect of nefiracetam to potentiate NMDA receptor currents via interaction with the glycine binding site (Moriguchi et al. 2003), allied with the evidence that activation of NMDA receptors can facilitate destabilisation (Bustos et al. 2010; Ortiz et al. 2015).

Given the complex mechanistic relationship between destabilisation, reconsolidation and extinction (AlmeidaCorrea and Amaral 2014; Cassini et al. 2017; Merlo et al. 2014), any potential therapeutic strategy that targets one of these processes has the potential to result in "off-target" effects on another process, leading to the possibility of maintaining or even enhancing the problematic memory (Lee et al. 2006; Tronson et al. 2006). Our results suggest that dual treatment with nefiracetam and mifepristone does not disrupt or facilitate cued fear memory extinction. Importantly, this lack of effect was observed under conditions that are appropriate for engaging extinction (Lee et al. 2006) and not due to the parameters of extinction training falling into the "null" or "limbo" space between destabilisation and extinction (Cassini et al. 2017; Merlo et al. 2014). This assumption is supported by the apparent effects of mifepristone and nefiracetam individually. However, these individual effects of mifepristone and nefiracetam indicate the need for caution when considering any translational application of the combined treatment.

The effect of nefiracetam to increase fear expression at test and the suggestion that this increase in fear occurs even under conditions of mifepristone administration indicate that preextinction nefiracetam disrupts extinction learning and/or consolidation. This is a novel observation, as to our knowledge, the effects of nefiracetam on extinction of any memory have not previously been assessed. Such a disruption of extinction contrasts with the apparent facilitation of destabilisation, and as such may be inconsistent with the idea of a common labilisation system (Almeida-Correa and Amaral 2014). However, it remains possible that nefiracetam modulates destabilisation and extinction via distinct mechanisms of action, potentially at both pharmacological and neuroanatomical levels. Regardless of the mechanism of action, the fearenhancing effect of nefiracetam alone raises concern that the therapeutic strategy of using nefiracetam to facilitate destabilisation might result in counterproductive effects on extinction.

In contrast, the apparent effect of mifepristone to reduce fear under conditions of extinction training further supports its potential benefit. A treatment that reduces fear expression irrespective of reactivation parameters would render that treatment less dependent upon understanding the boundary conditions of reconsolidation and extinction. However, it should be 
noted that the beneficial impact of mifepristone on extinction was rather modest, and it remains unlikely that mifepristone would have any effect in the "null point" between reconsolidation and extinction. Moreover, while infusion of mifepristone directly into the infralimbic cortex similarly enhanced the extinction of cued fear (Dadkhah et al. 2018), these results contrast somewhat with previous observations showing that intra-amygdala infusions of mifepristone did not directly affect extinction of fear-potentiated startle (Yang et al. 2006) and systemic injections of mifepristone did not affect the extinction of contextual fear (Ninomiya et al. 2010).

Ultimately, there is a need to explore the effects of mifepristone on extinction further, as well as determining the precise mechanisms of action of nefiracetam to enhance destabilisation and impair extinction. There is also the unanswered question of whether the apparent lack of effect of the combination of nefiracetam and mifepristone on extinction simply reflects the cancelling out of opposing effects. Importantly, the persistence of the disruptive effect across both reactivation and testing contexts is a key factor for translational efficacy. Moreover, as the present study was conducted exclusively on young male rats, there remains a need to determine whether the beneficial effects on fear memory expression generalise to other populations. However, the present results support the premise that a strategy of enhancing destabilisation and impairing reconsolidation via dual drug treatment has the potential for reducing fear expression without risking fear potentiation.

Acknowledgements The authors would like to thank David Barber for technical support.

Funding and Disclosure This research was supported by a Leverhulme Trust Research Project Grant to JL (RPG-2015-006).

\section{Compliance with ethical standards}

Conflict of interest On behalf of all authors, the corresponding author states that there is no conflict of interest.

Human and animal rights and informed consent The experiments comply with the United Kingdom Animals (Scientific Procedures) Act 1986, Amendment Regulations 2012.

Open Access This article is distributed under the terms of the Creative Commons Attribution 4.0 International License (http:// creativecommons.org/licenses/by/4.0/), which permits unrestricted use, distribution, and reproduction in any medium, provided you give appropriate credit to the original author(s) and the source, provide a link to the Creative Commons license, and indicate if changes were made.

\section{References}

Agren T (2014) Human reconsolidation: a reactivation and update. Brain Res Bull 105:70-82
Almeida-Correa S, Amaral OB (2014) Memory labilization in reconsolidation and extinction - evidence for a common plasticity system? J Physiol Paris 108:292-306

Ben Mamou C, Gamache K, Nader K (2006) NMDA receptors are critical for unleashing consolidated auditory fear memories. Nat Neurosci 9:1237-1239

Boccia MM, Acosta GB, Blake MG, Baratti CM (2004) Memory consolidation and reconsolidation of an inhibitory avoidance response in mice: effects of i.c.v. injections of hemicholinium-3. Neuroscience 124:735-741

Boccia MM, Blake MG, Acosta GB, Baratti CM (2006) Post-retrieval effects of icv infusions of hemicholinium in mice are dependent on the age of the original memory. Learn Mem 13:376-381

Bos MG, Beckers T, Kindt M (2014) Noradrenergic blockade of memory reconsolidation: a failure to reduce conditioned fear responding. Front Behav Neurosci 8:412

Brunet A, Poundja J, Tremblay J, Bui E, Thomas E, Orr SP, Azzoug A, Birmes P, Pitman RK (2011) Trauma reactivation under the influence of propranolol decreases posttraumatic stress symptoms and disorder: 3 open-label trials. J Clin Psychopharmacol 31:547-550

Bustos SG, Giachero M, Maldonado H, Molina VA (2010) Previous stress attenuates the susceptibility to midazolam's disruptive effect on fear memory reconsolidation: influence of pre-reactivation Dcycloserine administration. Neuropsychopharmacology 35:10971108

Cassini LF, Flavell CR, Amaral OB, Lee JLC (2017) On the transition from reconsolidation to extinction of contextual fear memories. Learn Mem 24:392-399

Dadkhah M, Abdullahi PR, Rashidy-Pour A, Sameni HR, Vafaei AA (2018) Infralimbic dopamine D2 receptors mediate glucocorticoidinduced facilitation of auditory fear memory extinction in rats. Brain Res 1682:84-92

de Lima MN, Presti-Torres J, Dornelles A, Scalco FS, Roesler R, Garcia VA, Schroder N (2011) Modulatory influence of dopamine receptors on consolidation of object recognition memory. Neurobiol Learn Mem 95:305-310

De Oliveira Alvares L, Crestani AP, Cassini LF, Haubrich J, Santana F, Quillfeldt JA (2013) Reactivation enables memory updating, precision-keeping and strengthening: exploring the possible biological roles of reconsolidation. Neuroscience 244:42-48

Debiec J, LeDoux JE (2004) Disruption of reconsolidation but not consolidation of auditory fear conditioning by noradrenergic blockade in the amygdala. Neuroscience 129:267-272

Doyle E, O'Boyle KM, Shiotani T, Regan CM (1996) Nefiracetam (DM9384) reverses apomorphine-induced amnesia of a passive avoidance response: delayed emergence of the memory retention effects. Neurochem Res 21:649-652

Dudai Y (2004) The neurobiology of consolidations, or, how stable is the engram? Annu Rev Psychol 55:51-86

Fattore L, Piva A, Zanda MT, Fumagalli G, Chiamulera C (2018) Psychedelics and reconsolidation of traumatic and appetitive maladaptive memories: focus on cannabinoids and ketamine. Psychopharmacology 235:433-445

Fernandez RS, Boccia MM, Pedreira ME (2016) The fate of memory: reconsolidation and the case of prediction error. Neurosci Biobehav Rev 68:423-441

Gazarini L, Stern CA, Piornedo RR, Takahashi RN, Bertoglio LJ (2015) PTSD-like memory generated through enhanced noradrenergic activity is mitigated by a dual step pharmacological intervention targeting its reconsolidation. Int J Neuropsychopharmacol:18

Heath FC, Jurkus R, Bast T, Pezze MA, Lee JL, Voigt JP, Stevenson CW (2015) Dopamine D1-like receptor signalling in the hippocampus and amygdala modulates the acquisition of contextual fear conditioning. Psychopharmacology 232:2619-2629

JASP Team (2016) JASP 
Jin XC, Lu YF, Yang XF, Ma L, Li BM (2007) Glucocorticoid receptors in the basolateral nucleus of amygdala are required for postreactivation reconsolidation of auditory fear memory. Eur $\mathrm{J}$ Neurosci 25:3702-3712

Kindt M, Soeter M, Vervliet B (2009) Beyond extinction: erasing human fear responses and preventing the return of fear. Nat Neurosci 12: 256-258

Kindt M, van Emmerik A (2016) New avenues for treating emotional memory disorders: towards a reconsolidation intervention for posttraumatic stress disorder. Ther Adv Psychopharmacol 6:283-295

Lee JLC, Amorim FE, Cassini LF, Amaral OB (2019) Different temporal windows for CB1 receptor involvement in contextual fear memory destabilisation in the amygdala and hippocampus. PLoS One 14: e0205781

Lee JLC, Flavell CR (2014) Inhibition and enhancement of contextual fear memory destabilization. Front Behav Neurosci 8:144

Lee JLC, Milton AL, Everitt BJ (2006) Reconsolidation and extinction of conditioned fear: inhibition and potentiation. J Neurosci 26:1005110056

Lin HC, Mao SC, Gean PW (2006) Effects of intra-amygdala infusion of $\mathrm{CB} 1$ receptor agonists on the reconsolidation of fear-potentiated startle. Learn Mem 13:316-321

Luthman J, Lindqvist E, Kojima H, Shiotani T, Tanaka M, Tachizawa H, Olson L (1994) Effects of nefiracetam (DM-9384), a pyrrolidone derivative, on brain monoamine systems. Arch Int Pharmacodyn Ther 328:125-144

Merlo E, Milton AL, Goozee ZY, Theobald DE, Everitt BJ (2014) Reconsolidation and extinction are dissociable and mutually exclusive processes: behavioral and molecular evidence. J Neurosci 34: 2422-2431

Merlo E, Ratano P, Ilioi EC, Robbins MA, Everitt BJ, Milton AL (2015) Amygdala dopamine receptors are required for the destabilization of a reconsolidating appetitive memory $(1,2)$. Eneuro 2

Moriguchi S, Marszalec W, Zhao X, Yeh JZ, Narahashi T (2003) Potentiation of N-methyl-D-aspartate-induced currents by the nootropic drug nefiracetam in rat cortical neurons. J Pharmacol Exp Ther 307:160-167

Muravieva EV, Alberini CM (2010) Limited efficacy of propranolol on the reconsolidation of fear memories. Learn Mem 17:306-313

Nader K, Schafe GE, Le Doux JE (2000) Fear memories require protein synthesis in the amygdala for reconsolidation after retrieval. Nature 406:722-726

Ninomiya EM, Martynhak BJ, Zanoveli JM, Correia D, da Cunha C, Andreatini R (2010) Spironolactone and low-dose dexamethasone enhance extinction of contextual fear conditioning. Prog NeuroPsychopharmacol Biol Psychiatry 34:1229-1235

Nishizaki T, Matsuoka T, Nomura T, Sumikawa K, Shiotani T, Watabe S, Yoshii M (1998) Nefiracetam modulates acetylcholine receptor currents via two different signal transduction pathways. Mol Pharmacol $53: 1-5$

Ortiz V, Giachero M, Espejo PJ, Molina VA, Martijena ID (2015) The effect of midazolam and propranolol on fear memory reconsolidation in ethanol-withdrawn rats: influence of d-cycloserine. Int J Neuropsychopharmacol 18:pyu082

Oyaizu M, Narahashi T (1999) Modulation of the neuronal nicotinic acetylcholine receptor-channel by the nootropic drug nefiracetam. Brain Res 822:72-79
Pitman RK, Milad MR, Igoe SA, Vangel MG, Orr SP, Tsareva A, Gamache K, Nader K (2011) Systemic mifepristone blocks reconsolidation of cue-conditioned fear; propranolol prevents this effect. Behav Neurosci 125:632-638

Ratano P, Everitt BJ, Milton AL (2014) The CB1 receptor antagonist AM251 impairs reconsolidation of Pavlovian fear memory in the rat basolateral amygdala. Neuropsychopharmacology 39:2529 2537

Sakurai T, Kato T, Mori K, Takano E, Watabe S, Nabeshima T (1998) Nefiracetam elevates extracellular acetylcholine level in the frontal cortex of rats with cerebral cholinergic dysfunctions: an in vivo microdialysis study. Neurosci Lett 246:69-72

Shanmugasundaram B, Korz V, Fendt M, Braun K, Lubec G (2015) Differential effects of wake promoting drug modafinil in aversive learning paradigms. Front Behav Neurosci 9:220

Soeter M, Kindt M (2015) An abrupt transformation of phobic behavior after a post-retrieval amnesic agent. Biol Psychiatry 78:880-886

Stern CA, Gazarini L, Takahashi RN, Guimaraes FS, Bertoglio LJ (2012) On disruption of fear memory by reconsolidation blockade: evidence from cannabidiol treatment. Neuropsychopharmacology 37: 2132-2142

Stiver ML, Jacklin DL, Mitchnick KA, Vicic N, Carlin J, O'Hara M, Winters BD (2015) Cholinergic manipulations bidirectionally regulate object memory destabilization. Learn Mem 22:203-214

Suzuki A, Mukawa T, Tsukagoshi A, Frankland PW, Kida S (2008) Activation of LVGCCs and CB1 receptors required for destabilization of reactivated contextual fear memories. Learn Mem 15:426433

Thomas E, Saumier D, Pitman RK, Tremblay J, Brunet A (2017) Consolidation and reconsolidation are impaired by oral propranolol administered before but not after memory (re)activation in humans. Neurobiol Learn Mem 142:118-125

Tronson NC, Wiseman SL, Olausson P, Taylor JR (2006) Bidirectional behavioral plasticity of memory reconsolidation depends on amygdalar protein kinase A. Nat Neurosci 9:167-169

Wideman CE, Jardine KH, Winters BD (2018) Involvement of classical neurotransmitter systems in memory reconsolidation: focus on destabilization. Neurobiol Learn Mem 156:68-79

Wood NE, Rosasco ML, Suris AM, Spring JD, Marin MF, Lasko NB, Goetz JM, Fischer AM, Orr SP, Pitman RK (2015) Pharmacological blockade of memory reconsolidation in posttraumatic stress disorder: three negative psychophysiological studies. Psychiatry Res 225: 31-39

Yang YL, Chao PK, Lu KT (2006) Systemic and intra-amygdala administration of glucocorticoid agonist and antagonist modulate extinction of conditioned fear. Neuropsychopharmacology 31:912-924

Yoshii M, Watabe S (1994) Enhancement of neuronal calcium channel currents by the nootropic agent, nefiracetam (DM-9384), in NG10815 cells. Brain Res 642:123-131

Yoshii M, Watabe S, Sakurai T, Shiotani T (1997) Cellular mechanisms underlying cognition-enhancing actions of nefiracetam (DM-9384). Behav Brain Res 83:185-188

Publisher's note Springer Nature remains neutral with regard to jurisdictional claims in published maps and institutional affiliations. 